\title{
Evaluation of Contact Pressure in Bending under Tension Test by a Pressure Sensitive Film
}

\author{
Luis Fernando Folle1, Lirio Schaeffer² \\ ${ }^{1}$ Centro Universitário Ritter dos Reis, Porto Alegre, Brazil \\ ${ }^{2}$ Universidade Federal do Rio Grande do Sul, Porto Alegre, Brazil \\ Email: luis_folle@uniritter.edu.br
}

How to cite this paper: Folle, L.F. and Schaeffer, L. (2016) Evaluation of Contact Pressure in Bending under Tension Test by a Pressure Sensitive Film. Journal of Surface Engineered Materials and Advanced Technology, 6, 201-214.

http://dx.doi.org/10.4236/jsemat.2016.64018

Received: September 16, 2016

Accepted: October 25, 2016

Published: October 28, 2016

Copyright $\odot 2016$ by authors and Scientific Research Publishing Inc. This work is licensed under the Creative Commons Attribution International License (CC BY 4.0).

http://creativecommons.org/licenses/by/4.0/

\begin{abstract}
The contact pressure acting on the sheet/tools interface has been studied because of growing the concern about the wear of tools. Recent studies make use of numerical simulation software to evaluate and correlate this pressure with the friction and wear generated. Since there are many studies that determine the coefficient of friction in sheet metal forming by bending under tension (BUT) test, the contact pressure between the pin and the sheet was measured using a film that has the ability to record the applied pressure. The vertical force applied to pin was also measured. The results indicate that the vertical force is more accurate to set the contact pressure that using equations predetermined. It was also observed that the contact area between the sheet and the pin is always smaller than the area calculated geometrically. The friction coefficient was determined for the BUT test through several equations proposed by various authors in order to check if there is much variation between the results. It was observed that the friction coefficient showed little variation for each equation, and each one can be used. The material used was the commercially pure aluminum, alloy Al1100.
\end{abstract}

\section{Keywords}

Coefficient of Friction, Sheet Metal Forming Process, Bending under Tension Test, Contact Pressure, Technology Applied to Design

\section{Introduction}

For the BUT test as in a stamping piece, the contact pressure is difficult to measure. There are efforts to determine this pressure, but currently only the result given by numerical simulation is known. Some studies have found that the profile of this pressure is not constant, i.e., there are two pressure peaks located near the beginning and end of 
the contact between the sheet and pin. It was also shown that this pressure profile occurs in the same way in the die radius. In 1997, Sniekers and Smits [1] demonstrated through finite element simulation of the BUT test that the contact pressure between the sheet and the pin had an irregular profile and that there were two major peaks of pressure.

Likewise, Kim et al. [2] also found that the pressure has an irregular profile by a finite element software. Furthermore, Kim et al. [2] found that the contact angle between the pin and the sheet is smaller than the bending angle of the array (90 degrees). Pereira et al. [3] conducted an analytical study also by simulating the contact pressure in the die radius during straining of a strap and found that the pressure peaks are due to high bending moments that occur in these areas making the central part of these peaks suffer loss of contact, greatly reducing the pressure in this region. These bending moments are generated by the spring back of the sheet. Pereira et al. [3] also found that the contact angle between the sheet and the die is less than $90^{\circ}$. In 2008, Pereira and Rolfe [4] made a more elaborated study on the evolution of contact pressure of a straight strip in the die radius region. It was shown that there is a transient region of contact pressure which corresponds to the beginning of sheet strain, after that the pressure stabilizes. It also demonstrated that the parameters that influence the pressure are the blank material ultimate tensile strength and the relationship between the die radius and the sheet thickness.

The results shown here are all based on finite element simulation, but in 2002, Coubrough et al. [5] measured the contact pressure by the addition of a film of piezoelectric material on the pin in the BUT test. The results obtained through this film were in Volt because this material had not been calibrated, however, this measure was proportional to the pressure value on the pin. Two tests were made, with the free pin (where the pin can rotate freely) and another with the fixed pin and what had been simulated [1]-[3] was proved. It was also observed that the beginning of contact between the sheet and the pin occurred at a previous angle, which is in accordance with simulations of Pereira et al. [3].

In 2007, Hoffmann et al. [6] conducted a study comparing the wear occurred in the die radius to seven combinations of sheet material and the tools. The wear that occurred in the die radius was measured and compared with numerical simulations. The results indicated that the greatest wear occurred precisely in those regions where the contact pressure between the sheet and die have high values and that these regions of greatest wear are located in the input and output of the bend radius of the sheet.

Thus, one objective of this work is to know what is the contact pressure acting on the bending radius of the pin in the BUT test by applying a film that has the ability to measure this contact pressure. Another objective is to calculate the coefficient of friction that acts during the BUT test for different levels of pressures.

\section{Experimental Analysis}

\section{1) Bending Under Tension Test}


The BUT test consists of bending a strip of sheet through a pin of predetermined radius and make it slide. For this, a force is applied at one end of the sheet so that there is relative movement between the sheet and pin. At the other end there is a force contrary to the movement in order to hold the sheet and be able to vary the contact pressure applied on the pin. Figure 1 shows a schematic view of this test. The force that generates the movement is called the pull force $\left(F_{1}\right.$ in Figure 1$)$ and the force which is applied in the opposite direction is the back tension force $\left(F_{2}\right.$ in Figure 1$)$. The pin of radius $r$ has the function to simulate the frictional radius stamping die because, in this region, the stresses are greatest according to [7].

In this test, there are two forces necessary to make the sheet to slide over the pin, one is the frictional force between the contact surfaces and the other is the force required for the bending and unbending the sheet. Since the purpose of the test is to know the frictional force between the contact surfaces, it runs in two steps. At first, the pin can rotate freely, so that there is no relative motion at the interface pin/sheet. This creates a condition of minimum friction, and the force required to move the sheet is due only to the force of bending and unbending the sheet. In the second step, the same pin is fixed preventing any movement. The force required to move the sheet is then made by bending force plus the friction forces. Thus, the bending force is removed and it is obtained as a result only the friction forces.

The machine used for measuring friction, see Figure 2, was designed in order to measure and evaluate the coefficient of friction in stamping and is based on the BUT

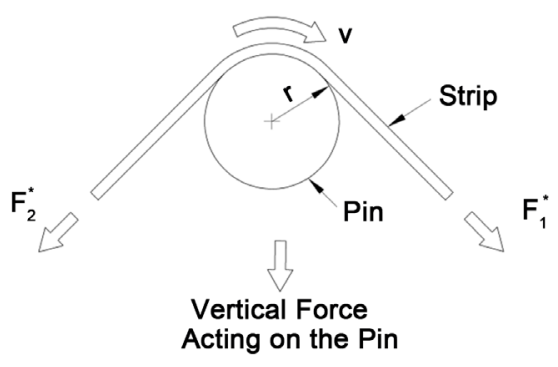

(a)

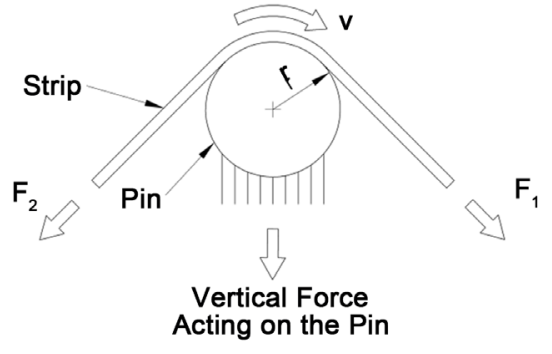

(b)

Figure 1. Schematic view of the BUT test. (a) Free rotating Pin; (b) Fixed Pin.

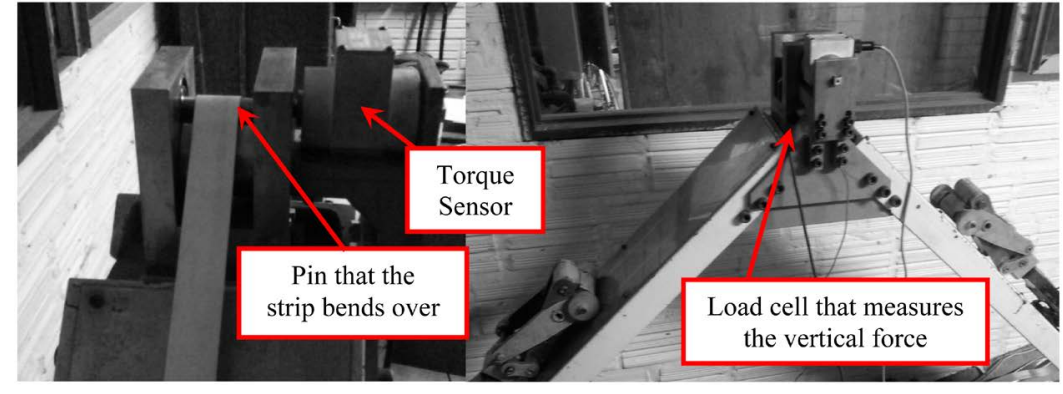

(a) (b)

Figure 2. Machine used for the BUT test. (a) detail view of the pin and (b) overall view of the machine. 
test. For this, there are two hydraulic cylinders which have the function of making a strip of sheet sliding over a pin. These hydraulic cylinders were mounted on a triangular structure that aims at decreasing the influence of vibration giving more stability to transmit forces during the test. On the upper vertex of the machine there is a pin that can be supported with or without bearings, see Figure 2. This pin passes on the strip of sheet with bending angle of 90 degrees.

On the left side of the machine there is a load cell coupled to the hydraulic cylinder, which has a role of measuring the pull force acting on the sheet. On the right side of the machine, there is another load cell that has the function of measuring the back tension force acting. Coupled with the pin there is a torque sensor, which is designed to measure the torque on the pin. Below the pin, there is a load cell that is designed to measure the vertical force on the pin.

\section{2) Equations Used to Determine the Friction Coefficient}

Just as there are variations in the basic form of the BUT test, the equations that are used to estimate the friction are also different. Some differences depend on the equipment that is used, but different authors have proposed different forms of the equations. The first approach to calculating the COF (Coefficient of Friction) was based on the pulley equations. In this case, the friction at the interface of the pin and strip is given by a natural logarithm of the ratio between the pull and the back forces, as can be observed in Equation (1).

$$
\mu=\frac{2}{\pi} \ln \frac{F_{1}}{F_{2}}
$$

where $F_{1}$ is the pull force and $F_{2}$ is the back force. The term $2 / \pi$ refers to the angle of 90 degrees between the forces $F_{1}$ and $F_{2}$. However, as discussed above, the test must be performed two times so that the bending force can be subtracted from the total force measured in the fixed pin. Therefore, a term was added to Equation (1). that refers to the bending strength of the sheet. This term, called the bending force $\left(F_{b}\right)$, is included in Equation (2). This force is obtained by subtracting the pull force from the back force, which are represented by $F_{1}^{*}$ and $F_{2}^{*}$ in Equation (3), respectively, when the test is performed with the pin free.

$$
\begin{gathered}
\mu=\frac{2}{\pi} \ln \frac{\left(F_{1}-F_{b}\right)}{F_{2}} \\
F_{b}=F_{1}^{*}-F_{2}^{*}
\end{gathered}
$$

As can be observed in Equations (1) and (2), the geometry of the test (the radius of the pin and the sheet thickness) has no contribution to the friction. Therefore, another equation was proposed to calculate the COF where the radius of the pin and sheet thickness are taken into account; this is given in Equation (4). This equation was used in several previous studies [8] [9] [10] [11].

$$
\mu=\frac{2}{\pi}\left[\frac{R+0.5 t}{R}\right] \ln \left[\frac{F_{1}-F_{b}}{F_{2}}\right]
$$


where $t$ is the sheet thickness and $R$ is the radius of the pin.

All the equations mentioned thus far are composed of a natural logarithm of the ratio of two or more forces. Another approach was proposed to calculate the friction and is given by Equation (5). This equation was used and described by [12] [13].

$$
\mu=\frac{2 \cdot\left(F_{1}-F_{2}-F_{b}\right)}{\Theta \cdot\left(F_{1}+F_{2}\right)}
$$

In Equation (5), $F_{1}$ is the pull force, $F_{2}$ is the back force, $F_{b}$ is the bending strength, and $\Theta$ is the sheet angle of bending.

In the work of [1] and [14], the authors made use of a torque sensor on the pin in the BUT test to eliminate the second step of the test when the pin is free to rotate. Equation (6), developed by Sniekers and Smits [1], shows how the COF is calculated with the torque measurement,

$$
\mu=\frac{\frac{F_{0} d}{R}}{\sqrt{F_{1}^{2}+F_{2}^{2}-\left(\frac{F_{0} d}{R}\right)^{2}}}
$$

where the term $F_{0} d$ represents the torque on the pin, $F_{1}$ is the pull force and $F_{2}$ is the back force.

The equation used by Andreasen et al. [14] in their work was developed to account for the friction stress that occurs at the pin-sheet interface and is given by Equation (7).

$$
\tau=\frac{2 T}{\pi W R^{2}}
$$

where $\tau$ is the friction stress, $T$ is the torque on the pin, $W$ is the width of the strip and $R$ is the pin radius.

It can be observed that to calculate the COF, several approaches have been proposed, but for calculating the contact pressure between the sheet and the pin, all authors use the same equation, given by Equation (8),

$$
p=\frac{F_{1}+F_{2}}{2 W R}
$$

where $p$ is the contact pressure, $F_{1}$ is the pull force, $F_{2}$ is the back force, $W$ is the width of the strip and $R$ is the pin radius.

The ratio of Equations (7) and (8) gives the COF, shown in Equation (9).

$$
\mu=\frac{\tau}{p}=\frac{4 T}{\pi R\left(F_{1}+F_{2}\right)}
$$

The contact pressure which is calculated by the Equation (8), which according to the authors [2] [8] [9] [11] [14] [15] [16] is the most common. However, a variation of this expression is shown in Equation (10) it was proposed in 1996 by Wilson, obtained from the work [12].

$$
P=\frac{F_{1}+F_{2}}{2 W R} \sin \frac{\theta}{2}
$$

There is also a third variation of Equation (8) that was proposed by Sube [17] and is 
shown in Equation (11).

$$
P=\frac{\left(F_{1}+F_{2}\right)-F_{b}}{2 W R}
$$

The material that was used in this study is commercially pure aluminum $\mathrm{Al} 1100$ and the properties are described in Table 1 .

\section{Results and Discussion}

\section{1) Evaluation of the Contact Pressure by Pressure Sensor}

With the intention of measuring the contact pressure which acts on the pin in the BUT test, a polymer film capable of measuring the pressure between two surfaces was used. This film is called Pressurex ${ }^{\circledR}$ and is marketed by the Sensor Products Inc Company.

The Pressurex ${ }^{\oplus}$ is a base film of mylar (polyester) containing a layer of micro capsules. The application of force on the film causes the microcapsules to rupture, producing an instantaneous image and high-resolution topography permanent pressure variation across the contact area (Figure 3 ). The color intensity of Pressurex ${ }^{\oplus}$ is directly related to the amount of pressure applied to it. The higher the pressure, the more intense the color. The numerical value of pressure is measured using a standard color intensity which is supplied by the manufacturer (see Figure 4). The Pressurex ${ }^{\oplus}$ film has a thickness of 0.1 to $0.2 \mathrm{~mm}$, which allows it to be applied to curved surfaces as well.

Through Pressurex ${ }^{\circledast}$ film, evaluation of the intensity of contact pressure both in stamped piece as the strip during the BUT test was made. Figure 5 shows the application

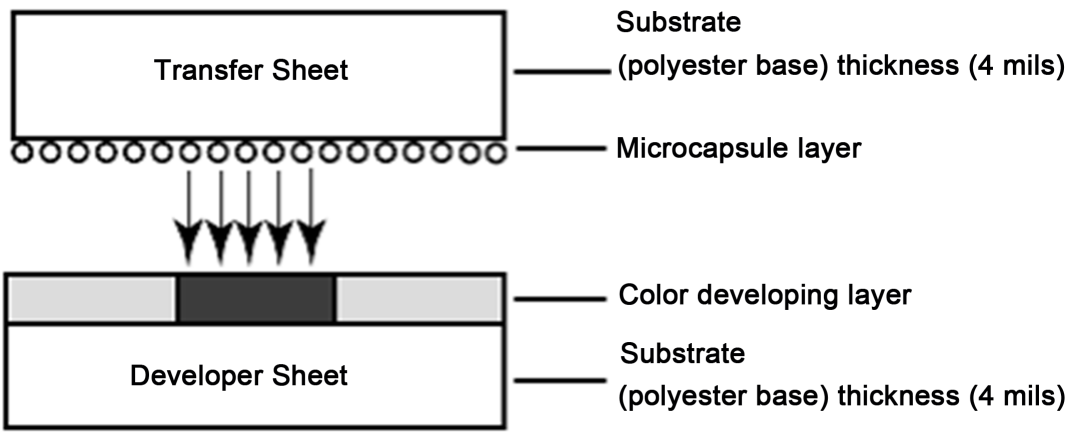

Figure 3. Cross view of the Pressurex ${ }^{\circledast}$ film.

Table 1. Properties of commercially pure aluminum Al 1100.

\begin{tabular}{ccc}
\hline \multicolumn{2}{c}{ Material Properties } & \\
\hline Young's Modulus & 69,000 & $\mathrm{~N} / \mathrm{mm}^{2}$ \\
Strain hardening exponent $(n)$ & 0.092 & \\
Strain hardening coefficient $(C)$ & 196.4 & \\
Anisotropy & 0.79 & $\mathrm{~N} / \mathrm{mm}^{2}$ \\
Yield stress $\left(k f_{0}\right)$ & 124 &
\end{tabular}




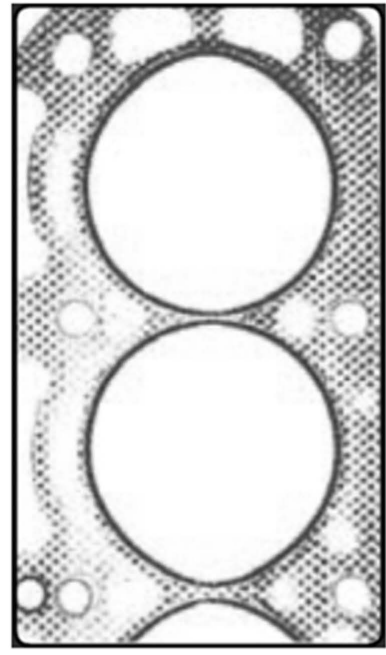

Pressure variation across a flange surface.

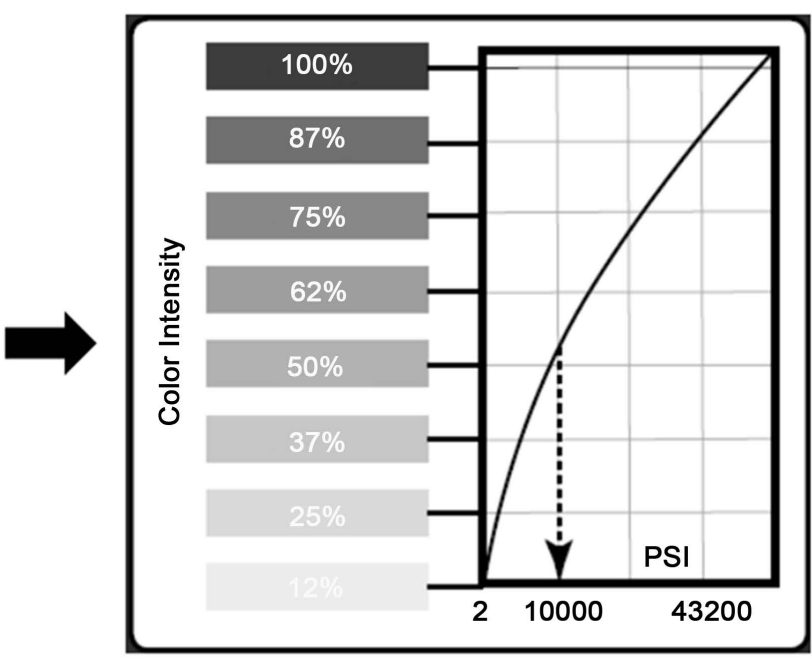

Color intensity reveals precise pressure magnitude.

Figure 4. Measurement of pressure by Pressurex ${ }^{\circledast}$.

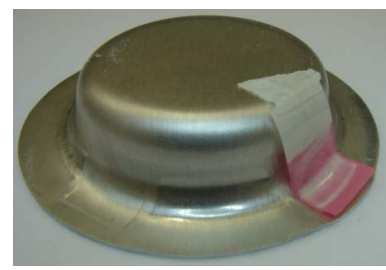

(a)

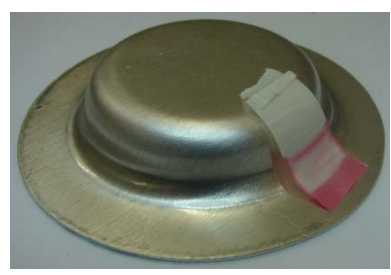

(b)

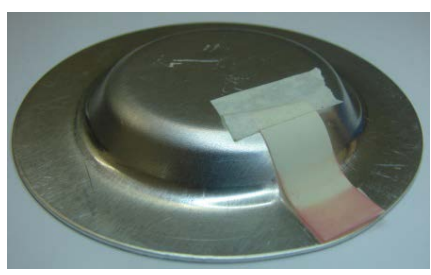

(c)

Figure 5. Application of the Pressurex ${ }^{\circledR}$ film in three stages of deformation of the piece, (a) 20 $\mathrm{mm}$ of the punch stroke; (b) $15 \mathrm{~mm}$ of the punch stroke; (c) $10 \mathrm{~mm}$ of the punch stroke.

of Pressurex ${ }^{\oplus}$ film at three stages of deformation of the stamped piece. As the film pressure acts under static conditions, it was necessary to measure the pressure with a minimum of slippage between the blank and die, so a preliminary deformation in the sheet was made prior to placing the film itself. Figure 6 shows the result for the BUT test with the pin fixed.

The results obtained by the application of pressure film are shown in Figure 7, both for stamped piece and to the pin. The pressure measurement was made with the film only for the piece with the greatest deformation (Figure 5(a)), since at this stage the piece has reached the maximum stamping force. The first important observation of Figure 7 is that the pressure level is reached around $30 \mathrm{MPa}$. Another observation is that the action of this pressure is not around the bend angle of 90 degrees, it acts on a region internal to that angle. This generates an error because the Equations (8), (10) and (11) consider the contacting area as being covered by all the bending angle, which was not observed. These results were already found by previous studies that were shown at the beginning of this work, but no direct measurement was made of the amount of pressure, the maximum that was obtained was a result of measurement in volts at work of [5] and other results were numerical simulations of this test. 


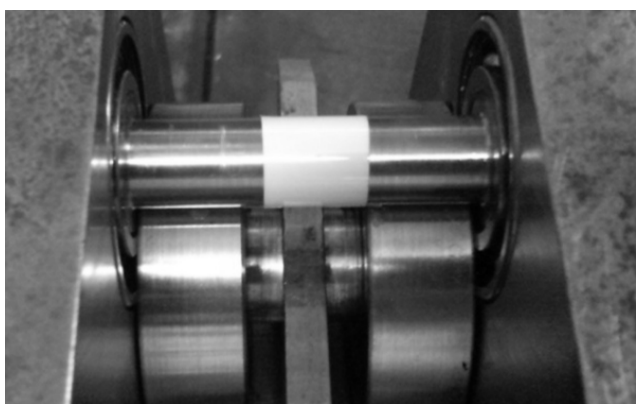

(a)
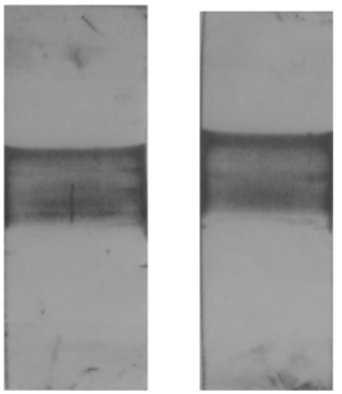

(b)

Figure 6. (a) Application of the Pressurex ${ }^{\circledast}$ film in the sheet strip during the BUT test and (b) films after the tests.

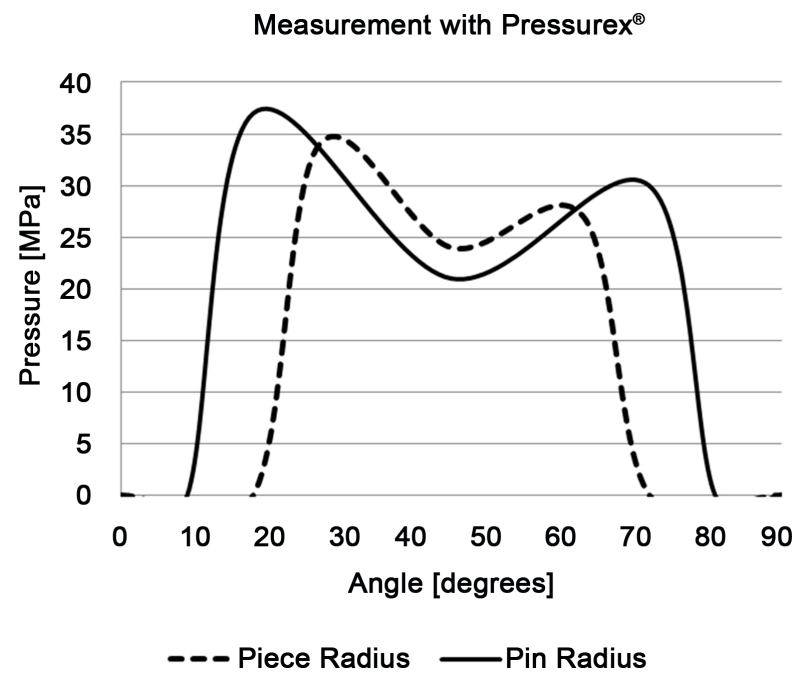

Figure 7. Results obtained in the pin and in the die radius by applying pressure film.

To get a more precise idea of the influence of contact pressure levels for different request of the sheet, measurements were made with Pressurex ${ }^{\circledast}$ film in the pin of BUT test for 3 levels of pressure. Figure 8 shows the strength of each side of the sheet for these three pressures, called "Maximum, Medium and Minimum". Tests were made with the fixed and free pin. The level "Maximum" corresponds to the pressure that is applied in the sheet very close to its rupture. The level "Minimum" is the minimum amount of pressure the machine applied to sheet, with is merely the force required to move the hydraulic cylinder without applying load. And the level "Medium" corresponds to an intermediate value between the Maximum and Minimum. By Figure 8 it is seen that when the pin is rotating freely, independent of pressure, the difference of the forces remained constant and that when the pin is fixed only the pullforce is increasing. In Figure 9 the torque value increases proportionally with increasing pressures.

As one of the aims of this study is to evaluate the contact pressure acting on the BUT test, the vertical force acting on the fixed and free pin was obtained. The contact pressure is then given by the ratio between the vertical force that acts on the sheet and the contact area of that force. Figure 10 shows the vertical force measured for the three 


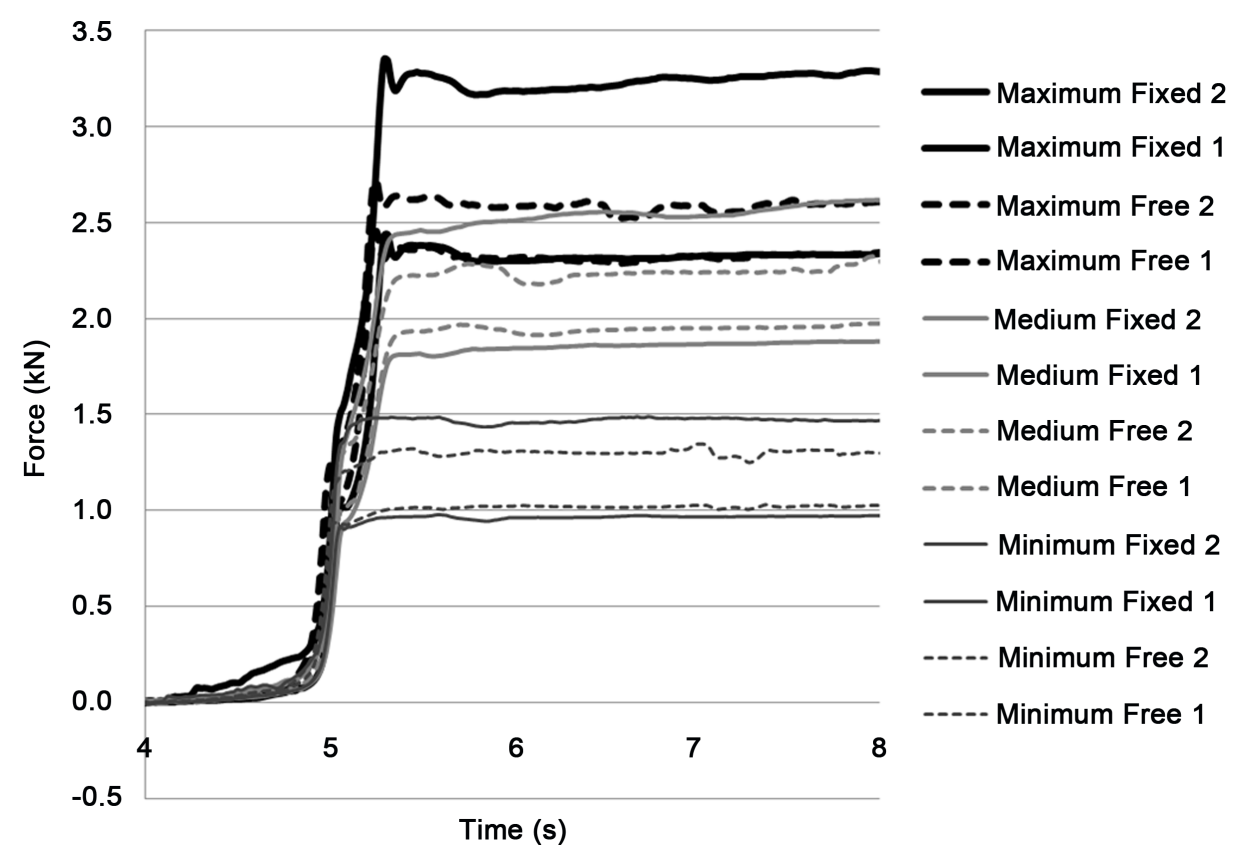

Figure 8. Force on each side of the sheet measured during the BUT test.

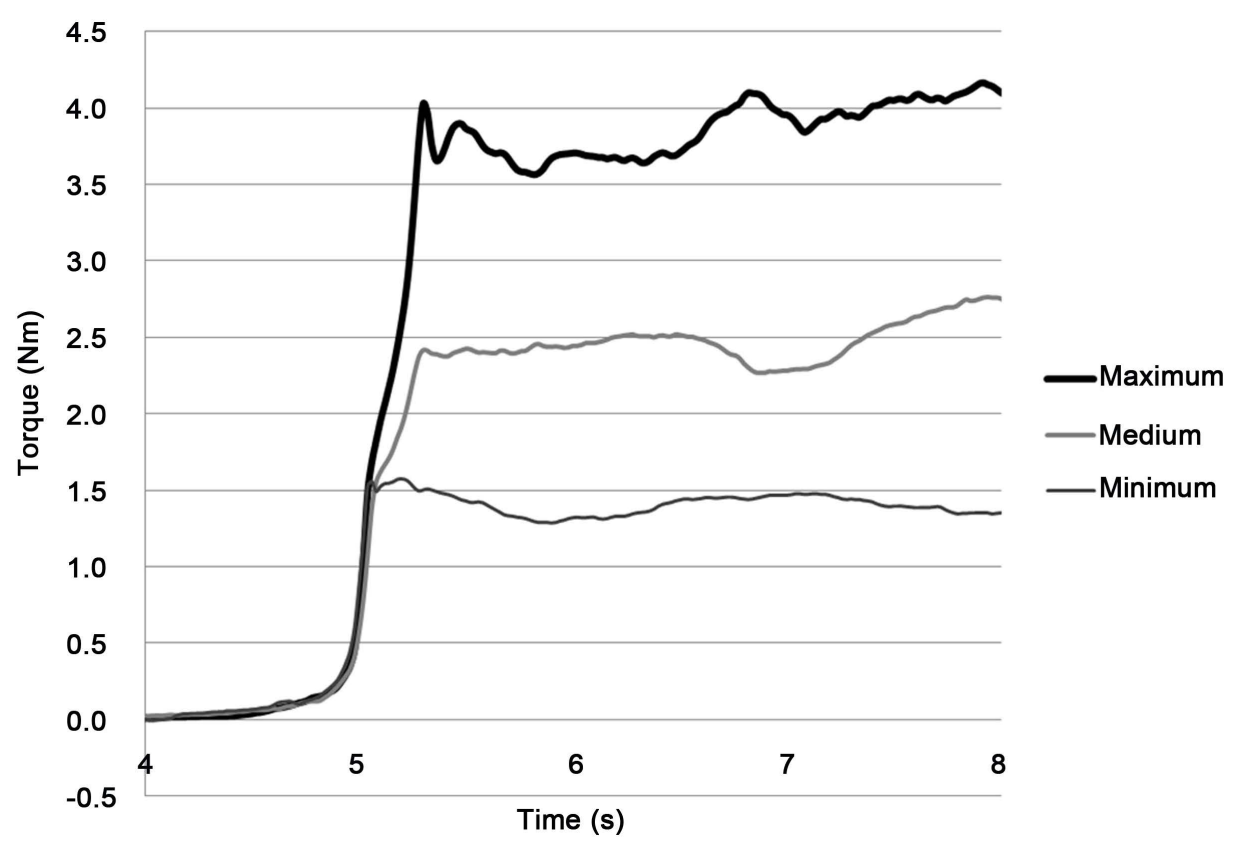

Figure 9. Measured torque on the pin during the BUT test.

pressure levels. It can be seen that the greater the forces acting on each side of the sheet, the greater the vertical force. It is possible also note that the measurements with pin free the pressure curves "Medium" and "Maximum" were very close, eventually being inverted of position. This is due to the load cell that makes an average of the pressures acting on the sheet. This becomes evident in Figure 11, which are the Pressurex ${ }^{\oplus}$ films obtained in these tests. In the case of measuring the "Medium" and "Maximum" pressure 


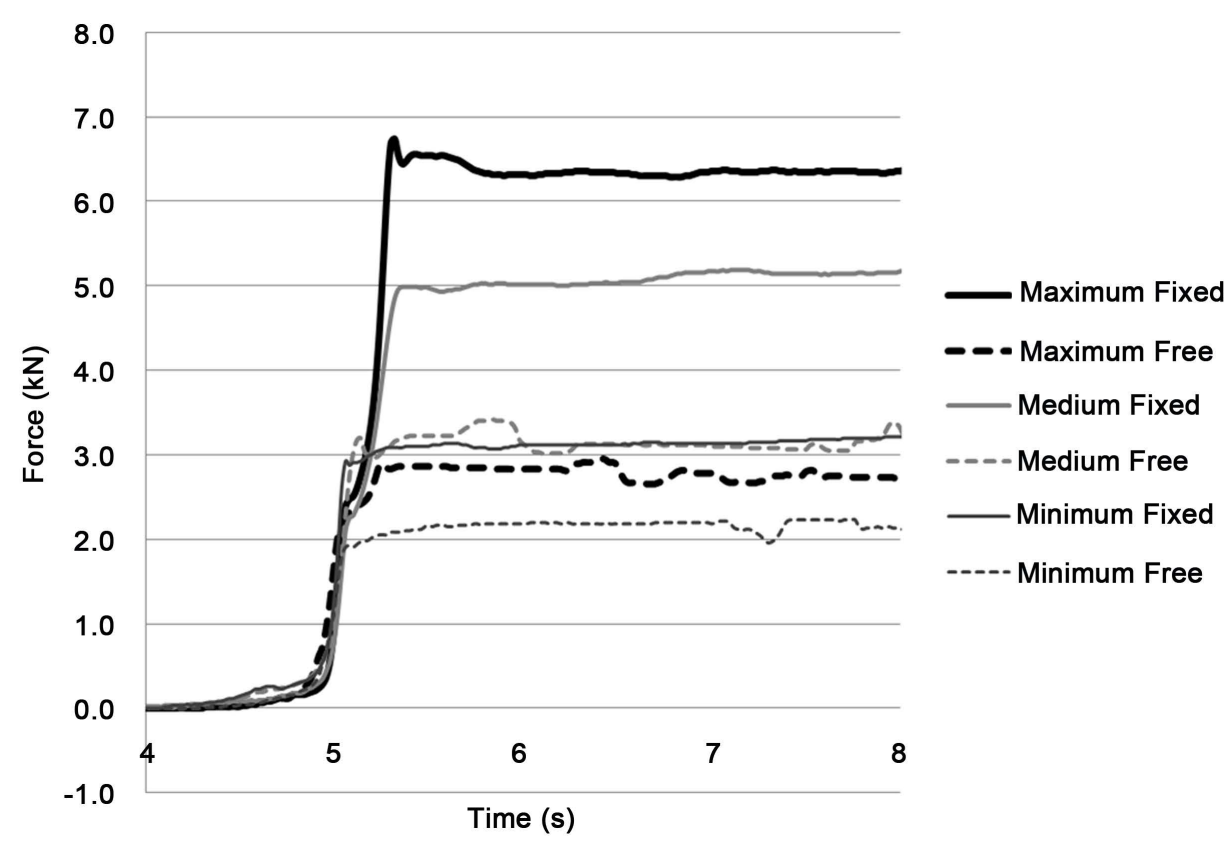

Figure 10. Measurement of vertical force on the pin during the BUT test.

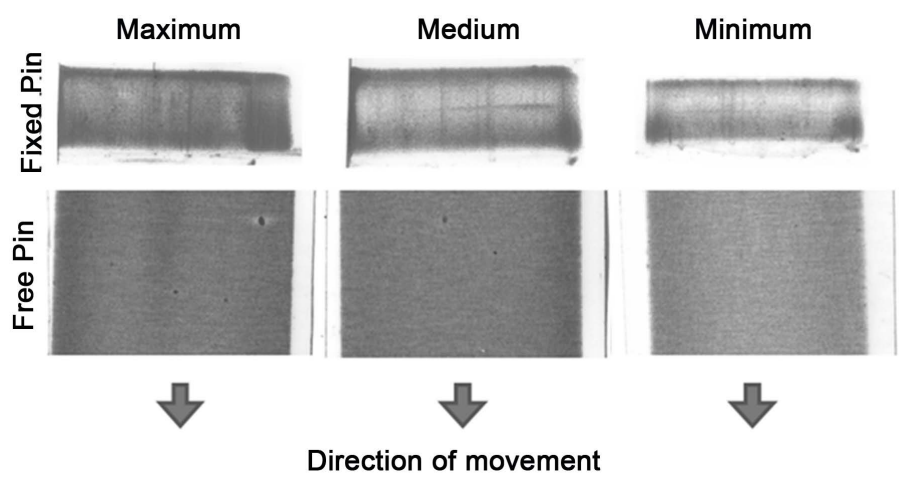

Figure 11. Pressurex ${ }^{\circledast}$ film obtained for each pressure level with fixed and free pin.

for the free pin it can be seen that the color, and therefore the pressure, are similar being in the order of $28 \mathrm{MPa}$ each one. Also in Figure 11 it is noteworthy that for measurements with the fixed pin, there are two characteristic peaks at the beginning and end of the bending angle of the sheet, which is in agreement with the studies of several authors, described at the beginning of this paper.

Figure 11 shows the visual result of the measurements, i.e. qualitatively, however, in Figure 12, these results are shown in quantitative values. In these figures it is evident that there are very pronounced peaks of contact pressure in the bending angle of the sheet. The dashed straight lines in both figures show how would be the average linear pressure peaks. Figure 12(a) shows the result when the pressure begins and ends in zero and Figure 12(b) shows what would be this mean linear when the starting and ending points are ignored. In this circumstance (Figure 12(b)) the average linear pressure is much higher than in Figure 12(a). 


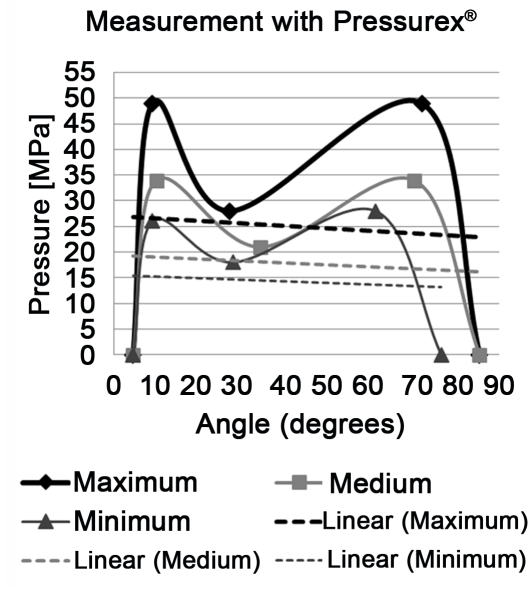

(a)

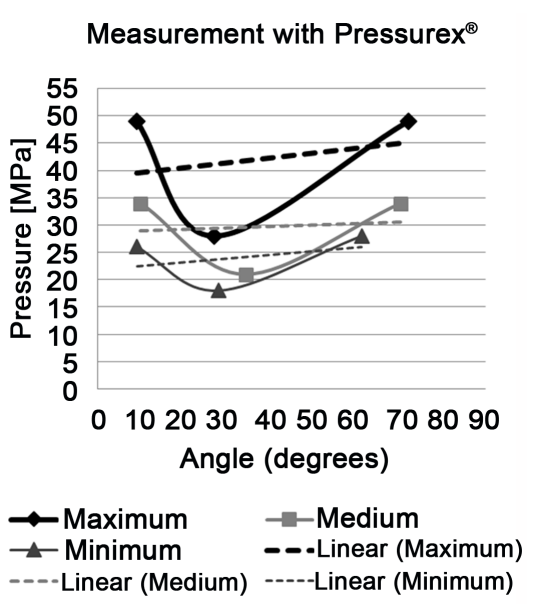

(b)

Figure 12. Results obtained by pressure Pressurex ${ }^{\circledR}$ films. The graph (a) shows the values considering the zero start and end points and graph (b) ignores these points.

With measurements of the vertical force on the pin is possible to estimate the contact pressure acting on the pin. The first important observation obtained by in Figure 12(a) is that the contact area of the pin with sheet does not work in all 90 degrees, so it must be corrected. Table 2 shows these results. The contact pressure between the sheet and the pin was calculated for each pressure level using Equations (8), (10) and (11), Equation (8) was also calculated with the correct contact area. Additionally, the contact pressure was calculated as the ratio of the measured vertical force on the pin with the real area of contact pressure. Two other situations corresponding to the minimum and maximum estimated pressure were analyzed. The estimated minimum pressures were obtained from Figure 12(a) through the linearization of the curve points considering the start and end zero points. The estimated maximum pressures of Figure 12(b) were obtained by linearization of the curve points without the start and end zero points. It is possible notices that if the start and end zero points are ignored there will be a difference between 60 and $70 \%$ compared to the vertical force measured. However if the start and end zero points are considered the difference will be minimal. Figure 13 shows the values of Table 2 graphically.

\section{2) Calculation of the Friction Coefficient through the BUT Test}

Through the measurements of torque and forces on each side of the sheet is possible to calculate the coefficient of friction for each equation described in Section 2. Table 3 shows these results. It can be seen that the friction coefficient remains almost unchanged independent of the level of pressure applied. It is noteworthy that the Pressurex $^{\circledast}$ film acts as an interface element separating the two surfaces, i.e., a dry solid lubricant, since the film must be used with the surfaces clean and dry. In other words, the Pressure ${ }^{\circledast}$ film keeps the ratio between the frictional force and the normal force always the same, regardless the pressure that is applied, and this is the expected behavior of a good lubricant performance, where the lubricating layer does not breaks with pressure. This indicates that a lubricant of good performance, should besides decreasing the 


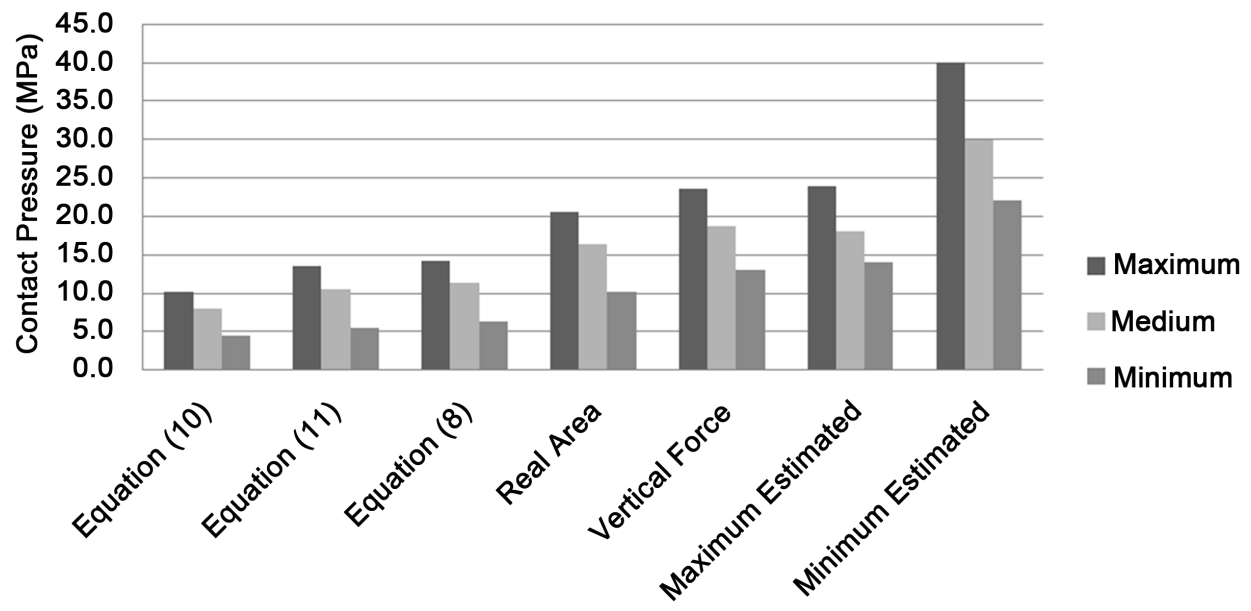

Figure 13. Contact pressure for several different ways to calculate.

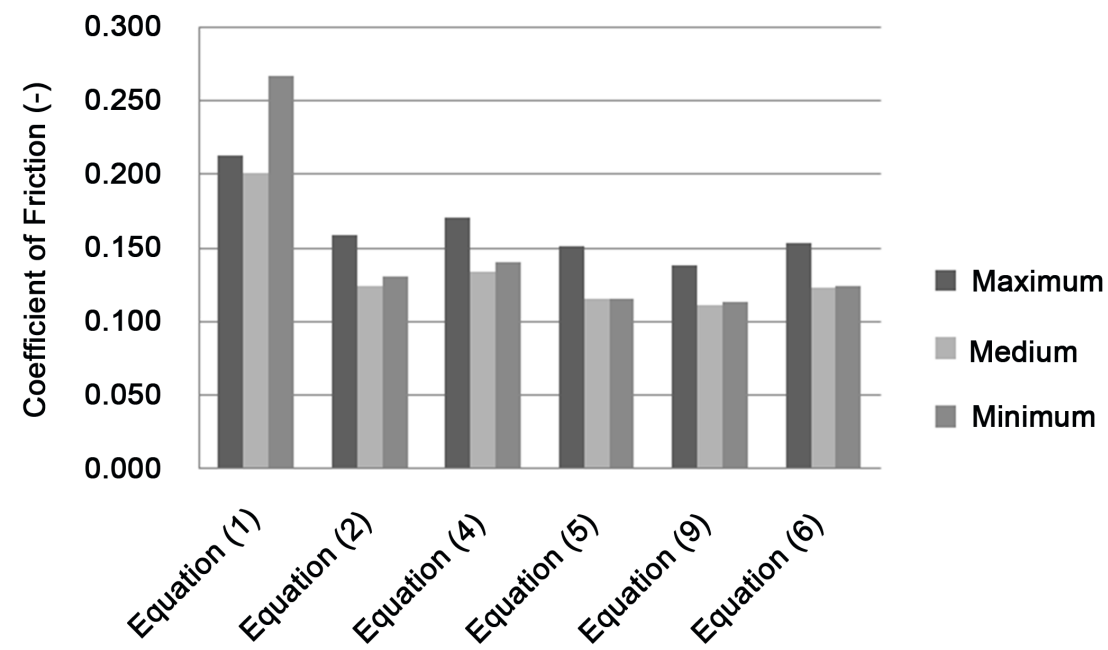

Figure 14. Friction coefficient calculated by different equations.

Table 2. Contact pressure for several different ways to calculate. Values in MPa.

\begin{tabular}{ccccccccc}
\hline $\begin{array}{c}\text { Pressure } \\
\text { Levels }\end{array}$ & $\begin{array}{c}\text { Equation } \\
(10)\end{array}$ & $\begin{array}{c}\text { Equation } \\
(11)\end{array}$ & $\begin{array}{c}\text { Equation } \\
(8)\end{array}$ & $\begin{array}{c}\text { Equation (8) } \\
\text { with Real } \\
\text { Area }\end{array}$ & $\begin{array}{c}\text { Vertical } \\
\text { Force. } \\
(\mathrm{VF})\end{array}$ & $\begin{array}{c}\text { Minimum } \\
\text { estimated } \\
(\text { EMi) }\end{array}$ & $\begin{array}{c}\text { Maximum } \\
\text { estimated } \\
(\text { EMa) }\end{array}$ & $\begin{array}{c}\text { Difference } \\
\text { between VF } \\
\text { and EMa (\%) }\end{array}$ \\
\hline Maximum & 10.1 & 13.6 & 14.3 & 20.6 & 23.5 & 24.0 & 40.0 & 70 \\
Medium & 8.0 & 10.6 & 11.3 & 16.4 & 18.8 & 18.0 & 30.0 & 60 \\
Minimum & 4.4 & 5.5 & 6.3 & 10.2 & 13.1 & 14.0 & 22.0 & 68 \\
\hline
\end{tabular}

Table 3. Friction coefficient calculated by different equations.

\begin{tabular}{ccccccc}
\hline Pressure Levels & Equations (1) & Equations (2) & Equations (4) & Equations (5) & Equations (9) & Equations (6) \\
\hline Maximum & 0.213 & 0.159 & 0.171 & 0.151 & 0.139 & 0.154 \\
Medium & 0.201 & 0.124 & 0.134 & 0.116 & 0.111 & 0.122 \\
Minimum & 0.267 & 0.131 & 0.141 & 0.115 & 0.113 & 0.124 \\
\hline
\end{tabular}


amount of friction, keeping it constant during the forming process. Figure 14 shows the values of Table 3 in graphical form. Equation (1) gives higher friction coefficients because it does not ignore the bending strength of the sheet. Thus, Equation (1) must not be used for calculating the coefficient of friction.

\section{Conclusions}

Regarding the measurement of contact pressure with the Pressurex ${ }^{\circledR}$ film:

The Pressurex ${ }^{\circledast}$ film proved to be effective in predicting the pressures associated with contact of the sheet with the pin, which is in full agreement with the results obtained by other authors. The finding of the contact pressure through the Pressurex ${ }^{\circledast}$ film showed that the measuring of vertical force on the pin is closer to the real values than the equations used so far for this.

Another important contribution is that the Pressurex ${ }^{\otimes}$ film shows what is the exact area of contact between the sheet and the pin and that will always be smaller than the area calculated geometrically, no matter the level of pressure applied. This brings an important correction in attempt to calculate the contact pressure.

Furthermore, in measurements with the Pressurex ${ }^{\oplus}$ film was found that the friction coefficient remained virtually constant for the various equations in three pressure levels. This suggests that a great lubricant performance is not necessarily one that generates the lowest levels of friction but one that can maintain constant friction with the variation of pressure applied.

\section{Acknowledgements}

The authors would like to thank $\mathrm{CNPq}$ for the financial support received.

\section{References}

[1] Sniekers, R.J.J.M. and Smits, H.A.A. (1997) Experimental Set-Up and Data Processing of the Radial Strip-Drawing Friction Test. Journal of Materials Processing Technology, 66, 216-223. http://dx.doi.org/10.1016/S0924-0136(96)02526-5

[2] Kim, Y.S., Jain, M.K. and Metzger, D.R. (2004) A Finite Element Study of Capstan Friction Test. AIP Conference Proceedings, Columbus, Ohio, 2264-2269.

[3] Pereira, M.P., Duncan, J.L., Yan, W. and Rolfe, B.F. (2009) Contact Pressure Evolution at the Die Radius in Sheet Metal Stamping. Journal of Materials Processing Technology, 209, 3532-3541. http://dx.doi.org/10.1016/j.jmatprotec.2008.08.010

[4] Pereira, M.P., Yan, W. and Rolfe, B.F. (2008) Contact Pressure Evolution and Its Relation to Wear in Sheet Metal Forming. Wear, 265, 1687-1699.

http://dx.doi.org/10.1016/j.wear.2008.04.042

[5] Coubrough, G.J., Alinger, M.J. and Van Tyne, C.J. (2002) Angle of Contact between Sheet and Die during Stretch-Bend Deformation as Determined on the Bending-under-Tension Friction Test System. Journal of Materials Processing Technology, 130-131, 69-75. http://dx.doi.org/10.1016/S0924-0136(02)00781-1

[6] Hoffmann, H., Nürnberg, G., Ersoy-Nürnberg, K. and Herrmann, G. (2007) A New Approach to Determine the Wear Coefficient for Wear Prediction of Sheet Metal Forming Tools. Production Engineering, 1, 357-363. http://dx.doi.org/10.1007/s11740-007-0065-1 
[7] ter Haar, R. (1996) Friction in Sheet Metal Forming, the Influence of (Local) Contact Conditions and Deformation. Ph.D. Thesis, University of Twente, Enschede.

[8] Wihlborg, A. and Gunnarsson, L. (2000) A Frictional Study of Uncoated EBT Steel Sheets in a Bending under Tension Friction Test. Wear, 237, 129-136.

http://dx.doi.org/10.1016/S0043-1648(99)00319-1

[9] Jonasson, M., Wihlborg, A. and Gunnarsson, L. (1998) Analysis of Surface Topography Changes in Steel Sheet Strips during Bending under Tension Friction Test. International Journal of Machine Tools \& Manufacture, 38, 459-467. http://dx.doi.org/10.1016/S0890-6955(97)00090-4

[10] Nanayakkara, N.K.B.M.P., Kelly, G. and Hodgson, P. (2005) Application of Bending under Tension Test to Determine the Effect of Tool Radius and the Contact Pressure on the Coefficient of Friction in Sheet Metal Forming. Materials Forum, 29, 114-118.

[11] Han, S.S. (1997) Influence of Tool Geometry on Friction Behavior in Sheet Metal Forming. Journal of Materials Processing Technology, 63, 129-133.

http://dx.doi.org/10.1016/S0924-0136(96)02612-X

[12] Fratini, L., Lo Casto, S. and Lo Valvo, E. (2006) A Technical Note on an Experimental Device to Measure Friction Coefficient in Sheet Metal Forming. Journal of Materials Processing Technology, 172, 16-21. http://dx.doi.org/10.1016/j.jmatprotec.2005.08.008

[13] Saha, P.K., Wilson, W.R.D. and Timsit, R.S. (1996) Influence of Surface Topography on the Frictional Characteristics of 3104 Aluminum Alloy Sheet. Wear, 197, 123-129. http://dx.doi.org/10.1016/0043-1648(95)06881-3

[14] Andreasen, J.L., Olsson, D.D., Chodnikiewicz, K. and Bay, N. (2006) Bending under Tension Test with Direct Friction Measurement. Proceedings of the Institution of Mechanical Engineers Part B-Journal of Engineering Manufacture, 220, 73-80. http://dx.doi.org/10.1243/095440505X32913

[15] Miguel, V., Coello, J., Calatayud, A., Manjabacas, M.C., Martinez, A. and Ferrer, C. (2009) An Approach to Evaluation of Sheet Bending Force under Successive Multiaxial Stress Condition. Journal of Materials Processing Technology, 209, 1588-1596. http://dx.doi.org/10.1016/j.jmatprotec.2008.04.016

[16] Hao, S., Klamecki, B.E. and Ramalingam, S. (1999) Friction Measurement Apparatus for Sheet Metal Forming. Wear, 224, 1-7. http://dx.doi.org/10.1016/S0043-1648(98)00288-9

[17] Sube, D. (2000) Possibilities and Results of Numeric and Experimental Simulation of Sheet Metal Forming Processes. In: Schaeffer, L., Ed., $3^{\circ}$ Conferência Nacional de Conformação de Chapas, Porto Alegre, 8 October 2000, 22-31. 
Submit or recommend next manuscript to SCIRP and we will provide best service for you:

Accepting pre-submission inquiries through Email, Facebook, LinkedIn, Twitter, etc. A wide selection of journals (inclusive of 9 subjects, more than 200 journals)

Providing 24-hour high-quality service

User-friendly online submission system

Fair and swift peer-review system

Efficient typesetting and proofreading procedure

Display of the result of downloads and visits, as well as the number of cited articles

Maximum dissemination of your research work

Submit your manuscript at: http://papersubmission.scirp.org/

Orcontact jsemat@scirp.org 